\title{
The BMJ Awards India: And the winners are . . . robotic spinal surgery, hospital stewardship of antibiotics, and primary care for hill tribes
}

\author{
Judges chose 10 nominations that showcased a breadth of medical innovation in India and that \\ have the potential to make substantial improvements to health in the country. Richard Hurley \\ reports from the inaugural BMJ Awards India in New Delhi
}

Richard Hurley deputy magazine editor, The BMJ

Last weekend saw the great and the good of Indian medicine come together in New Delhi for the very first BMJ Awards India. ${ }^{1}$ It was finally time to end the rumour and speculation: who had the judges decided most deserved a coveted trophy in recognition of his or her contribution to healthcare in the country?

Senior doctors and researchers, industry representatives, and government officials filled the Crystal Ballroom at the JW Marriott hotel in Delhi's Aerocity-and, if the guests and the setting were not already glamorous enough, a couple of Bollywood stars were also in attendance. Shibani Dandekar hosted the night, aided by the very definition of comic irreverence, Vir Das. "[He] has the audience in splits," Karan Thakur, a doctor and manager at Apollo Hospitals in Delhi, tweeted during the event. But there was also much serious business to attend to.

\section{Stiff competition}

Across 10 award categories the judges were looking for the work that most demonstrated novelty, relevance to India, scientific robustness, the potential to improve outcomes, and scalability. The day before the ceremony, representatives of the best 30 nominated individual doctors or teams had presented their work to a jury panel comprising BMJ and independent doctors. Jury members had them given them a thorough grilling to be absolutely sure who deserved to win, among particularly stiff competition. ${ }^{23}$

From more than 500 submissions, shortlisted nominations were selected by Anita Jain and Prashant Jha, who work for BMJ in India, and T Balajee, an independent healthcare expert.

\section{A long relationship}

Most of BMJ's senior management team from London were in town, including Fiona Godlee, The BMJ's editor in chief. Taking the stage, she explained that the ceremony was merely another step in a relationship between India and The BMJ that had existed "almost as long as the journal itself, sustained and strengthened by the mutual exchange of people and ideas."

Next to take the stage was Nata Menabde, a jury member and the World Health Organization's representative to India, who emphasised the country's need for health promotion-but she said that the health sector could not go it alone. She used the example of the huge burden to healthcare from road traffic crashes, the reduction of which, she said, would need input from the planning and transportation sectors.

\section{And the winners are ...}

The winner of Research Paper of the Year was a study published in the National Medical Journal of India that had estimated, using data from the National Family Health Survey, that more than a million new cases of tuberculosis a year could be attributed to undernutrition. ${ }^{4}$ The winners, Anurag Bhargava from Uttarakhand and coauthors, likened the immunodeficiency resulting from undernutrition-as a driver for the disease in India- to that resulting from HIV infection in Africa. They concluded, therefore, that tackling endemic undernutrition among adults was "a public health imperative" to reduce stubbornly consistent rates of tuberculosis in the country.

Pathik Patel, a senior resident at Karnavati School of Dentistry in Gandhinagar, was named Junior Doctor of the Year for advocating conservative and low cost dental interventions. Supriya Amey and colleagues came top in the Medical Team of the Year category, in recognition of a programme to promote good stewardship of antibiotics at Mumbai's Fortis Hospital, Mulund. An expert interdisciplinary team had been set up in response to rising antibiotic resistance, and it expected to reduce the harm to patients from hospital acquired infections while saving the hospital considerable costs. 


\section{Telecasting medical teaching}

Ravi Kumar Chittoria, of the Jawaharlal Institute of Postgraduate Medical Education and Research in Pondicherry, was commended in the Excellence in Medical Education category, for developing a seemingly simple solution to India's acute lack of medical teachers: free live telecasting of classes, workshops, and conferences, webcast to 160 medical colleges in south India, using a home video camera and the internet.

The winning Surgical Team of the Year was represented by Ravinder Uberoi, of Apollo Hospitals in New Delhi. It had successfully undertaken robotic spinal surgery to help a 10 year old boy with bone destruction as a result of spinal tuberculosis, in what the team described as a "world's first."

"He will now be able to go back to school after the summer vacations are over and not be limited due to the recovery process ... the lack of a big cut in the chest thanks to robotic surgery means he will be able to play cricket," said the team's submission.

The Quality Improvement in Healthcare award went to the paediatric cardiac unit at Amrita Institute of Medical Sciences, Kochi, led by Krishna Kumar. "Despite the challenges typically encountered in a limited resource environment, targeted quality improvement measures helped our unit to produce outcomes similar to those from developed nations after paediatric heart surgery," he said.

\section{Campaigning for tobacco control}

The prize in the Healthcare Advocacy category was awarded to the Voice of Tobacco Victims campaign (www.vovindia. org) — the brainchild of Pankaj Chaturvedi, a cancer surgeon at the Tata Memorial Hospital in Mumbai-which has mobilised nearly 170 cancer specialists throughout India. The motivation was the huge rates of oral cancers - the vast majority of the world's cases_-in a country with more than 300 million tobacco users. Bans on gutkha (a chewing tobacco product) should now protect more than 975 million people in India, and tobacco taxes have been increased for 700 million people.

"The campaign has played a pivotal role in the ban on gutkha all over India, a ban on chewing tobacco in seven states, and a ban on flavoured supari [pan masala without tobacco] in Maharashtra," Chaturvedi told The BMJ. "Our aim is to reduce the prevalence of tobacco use in India and eventually reduce tobacco related mortality."

Jha, on the jury panel said, "It almost broke all the rules of conventional marketing for a campaign - no celebrities, ghastly images, shoestring budgets - and yet they seem to be winning the war against the mighty chewable tobacco [gutkha]. Stunning!"

The Excellence in Preventive Health award went to the kNOw Diabetes project (http://knowdiabeteskerala.com/), which had brought health education with the aim of reducing "lifestyle diseases" to 800 schools and to some 220000 students, 10000 teachers, and 200000 adults in the Pathanamthitta and Alappuzha districts of Kerala.

\section{Challenging circumstances}

The Primary Healthcare in Challenging Circumstances award went to the Jawadhi Hills Health and Development Project in Tamil Nadu. Anuradha Rose's team from Christian Medical College in Vellore aims to meet the health needs of remote and underserved tribal people in the Eastern Ghats. Their intervention has seen huge improvements in maternal and infant mortality, childhood immunisation rates, and health seeking behaviour, as well as other outcomes such as health education and children remaining in formal education.

Leena Menghaney, a lawyer and coordinator for the Médecins Sans Frontières campaign for access to essential medicines in India, presented the award and took the opportunity to appeal for help with the current Ebola epidemic in west Africa. "The majority of patients are being treated by Doctors Without Borders," she said. "We're not asking for funds. We're asking for trained medical staff. If you are a doctor or a nurse, do join our team."

\section{A hung jury}

Judges were so torn between two nominations shortlisted for the Innovation in Healthcare Technology category that they had no choice but to present two awards. One went to a team represented by Sandeep Singh, of the Stanford India Biodesign Center at Delhi's All India Institute of Medical Sciences (AIIMS). It had invented a low cost intra-osseous device for emergency access to the adult circulatory system when peripheral intravenous access is impossible, which now has funding for a full clinical trial.

Sarman Singh, head of the division of clinical microbiology and molecular medicine at AIIMS, received the other award in this category for inventing a quick and accurate test for visceral leishmaniasis that costs only 40 rupees, which is based on a recombinant antigen from Leishmania donovani. The health minister, Harsh Vardhan, recently pledged eradication of the disease by 2015 , and the jury panel was impressed that the government plans to use this test in its National Vector Borne Disease Control Programme.

Sarman Singh commented, "That The BMJ found my innovation worth an award means a lot, and I am hopeful that, like the government of India, other governments of neighbouring countries will also take up our rapid test kits in their national kala-azar elimination programmes.

"Though I have received several national and international awards, I found this award significantly more prestigious and satisfying. I found it fairer, and it gives more visibility within and outside India."

\section{Everyone's a winner}

One of the jury members was Payal Bansal, head of the Institute of Medical Education Technology and Teachers' Training at Maharashtra University of Health Sciences, who told The BMJ, "[The judging was] an excellent opportunity to listen to some great work being carried out in our own country. The finalists' projects reflected the high benchmarks set by the selection committee and the rigour of the screening process."

During one intermission in proceedings, the comic Das joked, "Every one of you is a winner tonight-unless somebody else got the award." But, in all seriousness, that was far from how The BMJ's India team and the jury panels seemed to see it: the huge amounts of effort and time devoted to selecting the winning nominations was surely testament to the consistently high quality of submissions with huge potential to improve health in the country.

"I must admit that all of the finalists were winners, having read all of the work thrice now, through the three rounds of the selection process," said Jha, BMJ's clinical engagement editor. "It was a humbling experience to listen to exceptional presentations, and the awards event was fantabulous." 
Competing interests: I have read and understood BMJ policy on declaration of interests and have no relevant interests to declare.

See http://awards.bmjindia.com for full details of all the winners and video footage of the judging and event.

Follow @BMJIndia on Twitter for all the latest news, and use the hashtag \#BMJAwardsIndia.

Provenance and peer review: Commissioned; not externally peer reviewed.

1 Hurley R. The "Oscars of medicine" are coming to New Delhi: who will you nominate as a hero of Indian healthcare? BMJ 2014;349:94540.
2 D'Silva J. Judging the best of Indian healthcare. BMJ 2014;349:95454.

3 Hurley R. Which doctors have been shortlisted for the BMJ Awards India 2014? BMJ 2014;349:g5662.

4 Bhargava A, Benedetti A, Oxlade O, Pai M, Menzies D. Undernutrition and the incidence of tuberculosis in India: national and subnational estimates of the population attributable fraction related to undernutrition. Nat/ Med J India 2014;27:e4-9. www.nmji.in/OnlinePublication/02-27-3-OA-final\%20online.pdf.

5 Perappadan BS. Robotic surgery on 10-year-old with TB of the spine. The Hindu 1 August 2014. www.thehindu.com/news/cities/Delhi/robotic-surgery-on-10yearold-with-tb-of-thespine/article6270921.ece.

Cite this as: BMJ 2014;349:95803

(c) BMJ Publishing Group Ltd 2014 